\title{
USE OF QUALITY MANAGEMENT TOOLS AND METHODS IS ESSENTIAL TO SUPPORT EFFECTIVE GOVERNANCE OF HEALTHCARE ORGANISATIONS
}

\author{
Dinesh Arya
}

ACT Health, Canberra, Australia

Correspondence: Dinesh.Arya@act.gov.au

\section{ABSTRACT}

For healthcare organisations, a significant governance responsibility is for quality of health care provision. This is an important reason for governance boards to have good understanding of quality management and patient safety systems and processes that guide provision of all aspects of healthcare.

It is also important that there is structure to how governance activities are undertaken. Use of quality management tools and methods can provide that structure and support systematic and consistent governance decision making. Using quality management systems and frameworks should be a pre-requisite for effective governance.

\section{KEYWORDS}

governance, quality, improvement

\section{INTRODUCTION}

In healthcare settings, how an organization is governed is a key determinant of healthcare quality and patient safety as well as effectiveness of healthcare delivered. [1-12] Conversely, lack of good governance of quality and patient safety has been implicated in enquires into serious failures, for example at Mid-Staffordshire NHS Foundation Trust in the UK [13] and in the Forster Review of Queensland's health services in Australia. [14] There are also examples of financial collapse of high profile health systems and hospitals from the United States where inadequate governance by boards was seen as major contributor to financial mismanagement. [15]

The effectiveness of quality of governance systems, processes and practices is of critical importance to an organisation's success. [16]

It is proposed that governance systems and processes that are informed by quality management theory and practice can provide the necessary scaffolding for socially responsible, ethical and consistent governance of healthcare organisations. Integration of quality and governance functions also has the potential to ensure that appropriate and necessary systems and processes are in place that identify, monitor and improve governance protocols and systems on an ongoing and continuous basis.

\section{FOR CONSISTENCY IN GOVERNANCE PRACTICES, GOOD SYSTEMS AND PROCESSES ARE NECESSARY}

There is little disagreement about the need and importance effective governance to provide a clear direction to any organisation. Indeed, good quality management practice by definition incorporates concepts of ethical management and governance as well as social responsibility. $[17,18]$ In Australia, Health Boards are guided by an 'improvement guide' to meet the national standards for safety and quality. [19] Similar guidance documents provide guidance to the boards in 
similar health care systems across the globe e.g. the United Kingdom [20] and in the United States. [21]

However, an 'intention' to have good corporate governance may not be adequate to ensure effective governance function, including consistent management of vested interests, mismanagement and lack of accountability; consistency in consideration of issues, compliance with legislation; and effective decision making.

Integration of principles of quality management and governance has the potential to ensure that there is adequate process control and systems are in place that allow effective governance. These include consistent application of best practice, appropriate stakeholder involvement and consultation.

\section{WHY IS A SYSTEM DRIVEN BY QUALITY MANAGEMENT NECESSARY?}

There are a variety of quality management methodologies including Total Quality Management, Plan-Do-Check-Act, Lean Six Sigma, Kaizan, Poka-Yoka, Design of Experiments, Agile and Waterfall, a amongst others with commonalities in methods and methodologies across all. All quality management approaches share the philosophy that there must be a sequence or method to activities that are undertaken; measurement is a key to decision making; and, evaluation must be built into the method to ensure the system and process within it can be improved. Using quality management tools and methods is likely to give structure to the analysis, guide decision making and strengthen overall governance.

For healthcare organisations, a significant governance responsibility is that for quality of healthcare provision. [22] Understanding of quality and patient safety systems and processes is therefore almost a pre-requisite for the governance body. This enables understanding of how errors and omissions are identified, processes that are in place to ensure consistent clinical practice and clinical care delivery and how the organisation ensures it is a learning organization that is improving continuously. Not incorporating these quality improvement tools and methodology in governance and decision making in relation to healthcare provision, would be incongruous.

An important governance requirement is engagement of stakeholders. In today's world there is an imperative for stakeholders (i.e. those who have a vested interest in the decisions and actions) to be involved and engaged in wider governance of an organisation. For healthcare organisations (both public and private) essential stakeholders are healthcare consumers and the broader community. Even if the healthcare organisation is maintaining financial value, directors come under criticism for failing to demonstrate a sense of responsibility to healthcare consumers and the community. Health service governance must fully understand stakeholder interests and the impact of health services on the health of the community. This can be achieved using quality systems, tools, methods and processes that not only provide appropriate data and information but also allow the trust of stakeholders to be gained. Achieving transparency in relation to analysis and presentation of financial, quality and safety and key performance information is critical. Focus on continuously improving systems and processes also ensures consistency in application (often touted as the other side of the coin to corporate governance).

Yet another important aspect of a effective governance is evaluation. At least since the beginning of this century there has been a recognition that self-evaluation by the governing body and/or external evaluation of governance practices and decision making is essential. [23] Benefits of continuous evaluation of the governing boards have been noted and is now acknowledged as essential [24]. This methodology is firmly ingrained within quality management principles and systems.

\section{GOVERNANCE SYSTEMS AND QUALITY MANAGEMENT SYSTEMS HAVE SIMILAR AIMS}

In principle, the aim of corporate governance (stakeholder trust and high performance) and quality management (customer satisfaction and continuous improvement) are similar and complementary. Good governance and quality management systems are both concerned with setting and controlling standards as well as continuously improving processes to maintain (and if possible exceed) those standards.

Over the last two decades there have been several calls for hospital boards to focus on quality. [25, 26] In addition, it is really important that governance and quality improvement systems and processes also intricately linked. A strong link also ensures that governance system and decision making is informed and has the ability to 
understand implications of data on quality, effectiveness, efficiency and outcomes to inform decisions. Therefore, an effective quality system embedded within governance processes should enable the organization to be directed and controlled in a systematic and transparent manner as within a quality management framework, activities are carried out effectively and efficiently to develop products or to provide services at a level of quality that satisfies customers, while ensuring service delivery is at an appropriate time and price.

\section{THEN THERE IS THE ISSUE OF COMPLIANCE!}

There are a number of lessons in relation to compliance from non-healthcare settings that are of relevance for healthcare organisations. The post-mortem following collapse of major corporate players (e.g. Enron) and major movement in share values of other giants (e.g. WorldCom and Tyco) suggested (amongst other things) a closer focus on regulatory compliance. Recommendations to improve regulatory compliance by itself is not unusual as following a corporate collapse, recommendations to increased regulation are almost inevitable. Of interest though is that fact that these major corporations were seen to have 'good' corporate governance systems. More significant in the analysis was the fact that systems in place were inadequate to check misconduct or breach of governance protocols. What was identified was the need for such organizations to be prepared with tools, methods, compliance practices and policies to understand, on an ongoing basis, impact of regulation (decreased or increased) so that adjustments in practices and policies could be made on a continuous basis.

Inherent in quality management methods is the necessity to achieve high level of 'assurance.' Various tools are routinely used, including audits, survey and inspections to quality assure achievement of high level of compliance. If underperformance is identified, it triggers an alert and requires an investigation and a response. Incorporation of quality management tools and methods within governance processes do have the potential to provide the necessary structure and processes to ensure high level of compliance.

\section{CONCLUSIONS AND IMPLICATIONS FOR HEALTHCARE ORGANISATIONS}

Governance should be seen to encompass various structures, processes and relationships through which policies are conceptualized, developed, implemented and evaluated, legislative requirements are met, resources allocated and/or distributed and how decision makers are held accountable. Many healthcare organisations are governed by boards of governance and several different types of Boards exist, including voluntary, paid, nominated, appointed, elected and mixed. These boards have decision making and governance responsibilities, lead strategic planning, direct the management (or executive) teams and provide direction and control. Irrespective of the type and structure of governance arrangements, effective governance must ensure that the organisation is maintaining public trust and goodwill by demonstrating efficient and responsible use of all its resources.

An important aspect of effective governance is consistency with which matters are analysed, strategic decisions made, decisions implemented and how systematically post-implementation evaluations are undertaken. It is an effective and mature quality management system that can provide structure and support to ensure consistent governance practice.

\section{References}

1. Conway J. Getting boards on board: engaging governing boards in quality and safety joint commission. J Qual Patient Saf. 2008; 34:214-20.

2. Goeschel CA, Wachter RM, Pronovost PJ. Responsibility for quality improvement and patient safety: hospital board and medical staff leadership challenges. Chest. 2010; 138:171-8.

3. Levey S, Vaughn T, Koepke M, al. e. Hospital leadership and quality improvement: rhetoric versus reality. J Patient Saf. 2007; 3:9-15.

4. Gautam KS. A call for board leadership on quality in hospitals. Qual Manag Health Care. 2005; 14:18-30. 
5. Weiner BJ, Shortell SM, Alexander J. Promoting clinical involvement in hospital quality improvement efforts: the effects of top management, board, and physician leadership. Health Serv Res. 1997; 32:491-510.

6. Vaughn T, Koepke M, Kroch E, al. e. Engagement of leadership in quality improvement initiatives:

Executive quality improvement survey results. J Patient Saf. 2006; 2:2-9.

7. Jiang HJ, Lockee C, Bass K, al. e. Board oversight of quality: any differences in process of care and mortality? . J Healthc Manag. 2009; 54:54:15-30.

8. Joshi MS, Hines SC. Getting the board on board: engaging hospital boards in quality and patient safety. Jt Com J Qual Patient Saf 2006; 32:179-87.

9. Jha A, Epstein A. Hospital governance and the quality of care. Health Aff (Millwood). 2010; 29:182-7.

10. Clough J, Nash DJ. Health Care Governance for Quality and Safety: The New Agenda. Am J Med Qual. 2007;22(5):203-13.

11. Oetgen WJ. The Governing Board's Role in the Quality Agenda: An Overview. Prescriptions for Excellence in Health Care. 2009; 5:1-3.

12. Ramsay A, Fulop N, Fresko A, Rubenstein S. The Healthy NHS Board 2013: Review of Guidance and Research Evidence. Leeds: NHS Leadership Academy 2013.

13. Francis R. Report of the Mid Staffordshire NHS Foundation Trust Public Inquiry: executive summary. TSO Shop; 2013.

14. Forster P. Queensland health systems review. Brisbane: The Consultancy Bureau; 2005.

15. Kazemek EA, Knecht PR, Westfall BG. Effective boards: Working smarter to meet challenge. Trustee. 2000;53(5):18-23.

16. Carver J, Carver M. Carver's policy governance model in nonprofit organizations [monograph on the Internet] 2002 [cited 2004. Available from: http://www.carvergovernance.com/model.htm.

17. Jacques ML. The call for quality: doing right things right. Quality Progress. 1999; September:48-54.

18. Sciarelli S, editor Business Quality and Business Ethics, Business Excellence: Make it Happen! The 7th World Congress for Total Quality Management, 2002; Verona.
19. Australian Commission on Safety and Quality in Health Care. Guide to the National Safety and Quality Health Service Standards for health service organisation boards. Sydney: Australian Commission on Safety and Quality in Health Care; 2015.

20. National Quality Board. Quality Governance in the NHS National Quality Board - A guide for provider boards. London: Department of Health; 2011.

21. Belmont E, Haltom CC, Hastings DA, al. e. A New Quality Compass: Hospital Boards' Increased Role under the Affordable Care Act. Health Aff (Millwood). 2011;30(7):1282-9.

22. Pointer DD, Orlikoff JE. Board work: Governing healthcare organizations. San Francisco: Jossey-Bass; 1999.

23. Jaklevic MC. Letting the sunshine in. Mod Healthc. 2003;33(12):26-8.

24. Perrine L. Transforming board meetings helps heal a hospital. 2003 [cited 2004. Available from: http://www.hospitalconnect.com/.

25. National Quality Forum. Hospital governing boards and quality of care: a call to responsibility. Washington (DC); 2004 December 2, 2004.

26. Institute for Healthcare Improvement. Getting boards on board Cambridge (MA): IHI; 2008 [Available from: http://www.ihi.org//HI/Programs/. 